\title{
Arando surcos: incorporación de las mujeres indígenas como académicas en dos universidades públicas mexicanas
}

\section{Resumen}

El aumento paulatino y lento del número de mujeres indígenas en las Instituciones de Educación Superior (IES) es una constante. Sin embargo, la literatura sobre las mujeres indígenas que ingresan a laborar a las universidades es prácticamente inexistente. Por tanto, la presente investigación tiene como finalidad aportar al estudio sobre las académicas que se auto adscriben como parte de un pueblo indígena. Para el presente trabajo se entrevistó a un total de catorce académicas en dos universidades ubicadas en Estados con alta presencia de población indígena: Yucatán y Veracruz. Las universidades a las cuales pertenecen son la Universidad Autónoma de Yucatán (UADY) y la Universidad Veracruzana Intercultural (UVI). El objetivo general es identificar y explicar las principales problemáticas y estrategias de las que hicieron uso un grupo de mujeres que se autodefinen como pertenecientes a un pueblo indígena en su ingreso a la academia.

Palabras clave: Indígenas; Académicas; Género; Educación.

\section{Abstract}

Although gradually and slowly, the number of indigenous women in Higher Education Institutions (HEI) is constantly increasing. However, literature on indigenous women who enter to work at universities is practically non-existent. Therefore, the purpose of this research is to contribute to the study of female academics that self-identify as part of an indigenous people. For the present work, a total of fourteen female academics was interviewed in two universities located in states with a high presence of indigenous population: Yucatan and Veracruz. The universities to which they belong are the Autonomous University of Yucatan (UADY) and the Universidad Veracruzana Intercultural (UVI). The general objective is to identify and explain the main problems and strategies used by a group of women who define themselves as belonging to an indigenous people during their time in the educational system and entering the academy.

Keywords: Indigenous; Academic; Gender; Education.

POR NORMA MOLINA FUENTES. Doctora por el Centro de Investigación de Estudios Avanzados del Instituto Politécnico Nacional (CINVESTAV-IPN). norma8291@hotmail.com 


\section{Resumo}

O incremento, mesmo paulatino e divagar, do número de mulheres indígenas nas Instituições de Educação Superior (IES) é constante. Embora a literatura sobre as mulheres indígenas que conseguem entrar a trabalhar nas universidades é praticamente inexistente. Por tanto, a presente pesquisa tem como finalidade aportar ao estudo sobre as acadêmicas que se auto adscrevem como parte de uma comunidade indígena. Para o presente trabalho entrevistou-se um total de quatorze académicas em duas universidades localizadas nos estados com alta presencia de população indígena: Yucatán e Veracruz. As universidades as quais elas pertencem são a Universidade Autónoma de Yucatán (UADY) e a Universidade Veracruzana Intercultural (UVI). O objetivo geral é identificar e explicar as principais problemáticas e estratégias que utilizaram um grupo de mulheres, que se autodefinem como membros de uma comunidade indígena, na sua entrada à academia.

Palavras chave: Acadêmicas; Indígenas; Gênero; Educação.

\section{Introducción}

El presente artículo forma parte de una investigación más amplia contenida en mi tesis doctoral, cuyo tema de investigación versaba sobre la trayectoria educativa, ingreso y trayectoria académica de un grupo de mujeres indígenas relacionadas con su condición étnico-lingüística y de género. Dicha investigación se abordó desde la perspectiva decolonial y de género. Para analizar el colonialismo interno de la sociedad mexicana se contemplaron las condiciones socioeconómicas y las experiencias migratorias - de primera o segunda generación- de las académicas. Se recurre a la colonialidad del saber para hacer visible la forma de conocimiento eurocéntrica y monolingüística -en español-bajo la cual fueron educadas. Igualmente, se analizaron las implicaciones de su condición étnica y lingüística en su paso por el sistema educativo y en su ingreso y trayectoria como académicas.

A lo largo de este escrito se exponen los hallazgos de uno de los apartados de la tesis que mostraron los elementos que incidieron en el ingreso de las entrevistadas a la Universidad Autónoma de Yucatán (UADY) y la Universidad Veracruzana Intercultural (UVI). Es desde este marco de referencia que la presente investigación pretende dar respuesta a las siguientes preguntas: ¿qué factores incidieron en su incorporación como académicas? Y, ¿hubo "concesiones" desde la colonialidad del saber que les permitieron capitalizar su condición étnica o lingüística? Se parte de la hipótesis de que, una vez superados los obstáculos con los que se enfrentaron en niveles anteriores de escolarización, su condición étnico-lingüística puede dejar de tener una connotación negativa para su formación, e incluso, puede convertirse en un capital cultural susceptible de ser aprovechado conforme a una lógica de "concesiones" que otorgó el Sistema de Educación Superior (SES) mexicano a ciertas Instituciones de Educación Superior (IES).

Aníbal Quijano (2007) define la colonialidad como un patrón mundial de dominación dentro del modelo capitalista, fundado en una clasificación racial y étnica de la población del planeta que opera en distintos ámbitos. Según el autor, la colonialidad es una estructura de dominación y explotación que se inicia con el colonialismo, pero que se extiende hasta 


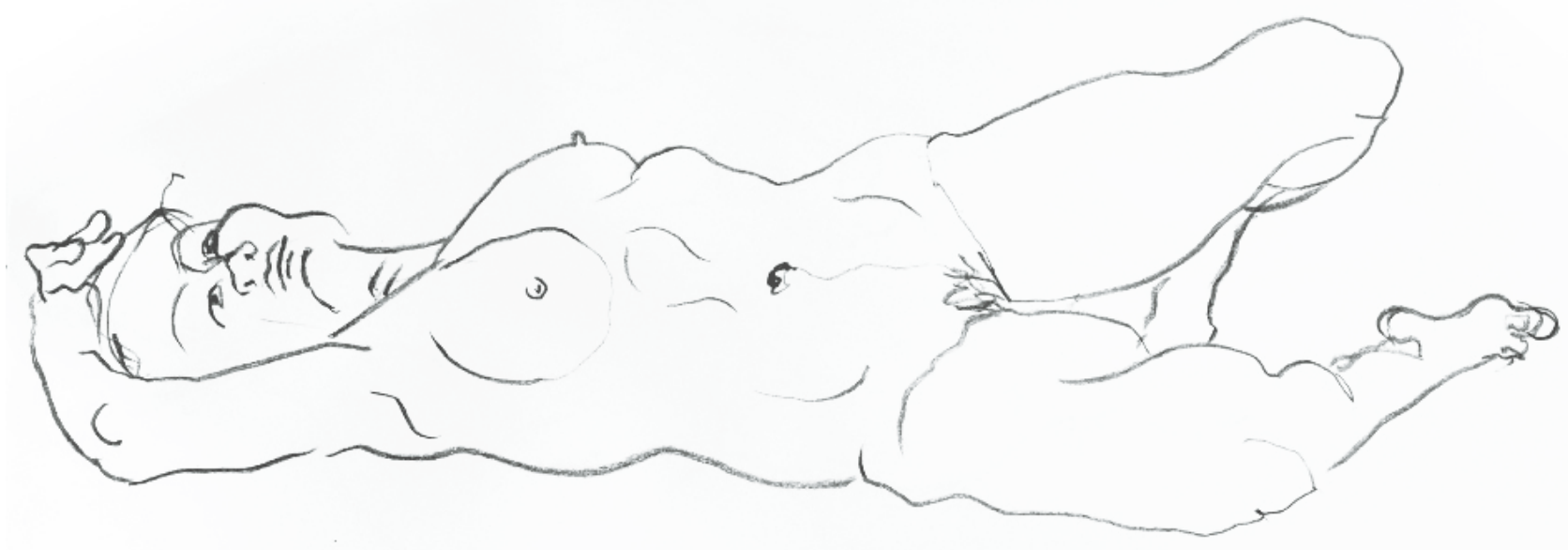

hoy día como su secuela. En esta misma línea, Enrique Dussel (1992) argumenta que la colonización se refiere al proceso de imperialismo y ocupación territorial de pueblos que efectúa un poder conquistador por medio del uso de la violencia. El colonialismo se refiere a la ideología que justifica y legitima el orden asimétrico y hegemónico establecido por el poder colonial. En otras palabras: "con América (Latina) el capitalismo se hace mundial, eurocentrado y la colonialidad y la modernidad se instalan, hasta hoy, como los ejes constitutivos de este particular modelo de poder" (Quijano, 2007, p.91).

\section{¿Quiénes son las académicas indígenas?}

Conocer los orígenes de las académicas permitió entender, entre otros temas, cómo se han fraguado sus historias, su paso por la escolaridad formal - las principales problemáticas que enfrentaron-, las consecuencias de la migración fuera de sus comunidades; por ejemplo, su relación con el hecho de hablar o no la lengua, así como los motivos de sus padres para trasmitirla o no a sus hijas. A modo de generalidad, se anotó que ocho de nuestras entrevistadas son originarias del Estado de Yucatán, tres de Veracruz y una más del Estado de
Querétaro. La mayoría, diez de ellas, son la primera generación en migrar de sus pueblos de origen; tres más, la segunda. Nueve de ellas son hablantes de sus idiomas maternos; dos más, lo entienden, pero no lo hablan, y tres no entienden ni hablan el idioma de sus padres. El cuadro 1 permite mostrar una síntesis de esos rasgos.

Los grados alcanzados por las académicas reflejan éxito escolar. Cinco de ellas cuentan con estudios de doctorado - algunas están en proceso de titulación-. Ocho más cuentan con grado de maestría, y dos más con licenciatura. Cuando me refiero a éxito escolar, hablo de la medida a través de los grados académicos que alcanzaron en comparación, no sólo con la población indígena o con sus respectivas etnias, sino con la población en general.

El tema migratorio ligado a la escolaridad es una constante a la que apuntan los estudios sobre los profesionistas, líderes políticos e intelectuales indígenas. Cristina Oehmichen (1999) señala que las migraciones de las mujeres se encuentran más condicionadas que las de los varones por la etapa en su trayectoria de vida, por su posición en el hogar, por su estado civil, por la presencia de hijos y pareja y por la estructura familiar. Así, el primer filtro que sortearon algunas de ellas fue contar con la aprobación de su entorno para irse de casa 
Cuadro 1. Datos generales de las académicas indígenas

\begin{tabular}{|c|c|c|c|c|c|c|}
\hline \multirow{4}{*}{ Etnia } & Lengua & Edad & $\begin{array}{c}\text { Migración } \\
\text { generación }\end{array}$ & Estado civil & Hijos(as) \\
\hline \multirow{4}{*}{ UVI } & Náhuatl & Entiende/habla & 31 & Primera & Unión libre & No \\
\cline { 2 - 7 } & Náhuatl & Entiende/habla & 28 & No migró & Soltera & No \\
\cline { 2 - 7 } & Zapoteca & Entiende/no habla & 34 & Primera & Soltera & No \\
\cline { 2 - 7 } & Totonaco & Entiende/habla & 37 & Primera & Casada & 1 \\
\cline { 2 - 7 } & Popoluca & Entiende/habla & 26 & Primera & Soltera & No \\
\cline { 2 - 7 } & Nañuu & Entiende/habla & 35 & Primera & Casada & 2 \\
\hline \multirow{4}{*}{ UADY } & Maya & No entiende/no habla & 38 & Segunda & Casada & No \\
\cline { 2 - 7 } & Maya & No entiende/no habla & 41 & Segunda & Soltera & No \\
\cline { 2 - 7 } & Maya & No entiende/no habla & 40 & Segunda & Casada & No \\
\cline { 2 - 7 } & Maya & Entiende/habla & 54 & Primera & Casada & No \\
\cline { 2 - 7 } & Maya & Entiende/no habla & 53 & Primera & Soltera & No \\
\cline { 2 - 7 } & Maya & Entiende/habla & 73 & Primera & Soltera & No \\
\cline { 2 - 7 } & Maya & Entiende/habla & 28 & Primera & Soltera & No \\
\cline { 2 - 7 } & Maya & Entiende/habla & 58 & Primera & Casada & 1 \\
\hline
\end{tabular}

Fuente: elaboración propia con base en información recabada durante la investigación.

Cuadro 2. Datos académicos de ingreso a la UADY

\begin{tabular}{|c|c|c|c|}
\hline Edad de ingreso & Año en que ingresó & Años laborando & Grado con el que ingresó \\
\hline 36 & 1977 & 37 & $\mathrm{Ls} / \mathrm{t}$ \\
\hline 27 & 1983 & 31 & $\mathrm{Ls} / \mathrm{t}$ \\
\hline 34 & 1994 & 20 & $\mathrm{~L}$ \\
\hline 24 & 1985 & 29 & $\mathrm{~L} \mathrm{~s} / \mathrm{t}$ \\
\hline 27 & 2000 & 14 & $\mathrm{M} \mathrm{s} / \mathrm{t}$ \\
\hline 28 & 2002 & 12 & $\mathrm{M}$ \\
\hline 24 & 2000 & 14 & $\mathrm{M} \mathrm{s} / \mathrm{t}$ \\
\hline 23 & 2009 & 5 & $\mathrm{~L}$ \\
\hline
\end{tabular}

$\mathrm{L}=$ licenciatura; $\mathrm{M}$ = maestría; $\mathrm{L} \mathrm{s} / \mathrm{t}$ = licenciatura sin terminar; $\mathrm{M} \mathrm{s} / \mathrm{t}$ = maestría sin terminar. Fuente: elaboración propia con base en información recabada durante la investigación.

Cuadro 3. Datos académicos de ingreso a la UVI

\begin{tabular}{|c|c|c|c|}
\hline Edad de ingreso & Año de ingreso & Años laborando & Grado con el que ingresó \\
\hline 27 & 2004 & 10 & $\mathrm{~L}$ \\
\hline 34 & 2013 & 1 & $\mathrm{M}$ \\
\hline 24 & 2004 & 10 & $\mathrm{~L}$ \\
\hline 29 & 2012 & 2 & $\mathrm{M}$ \\
\hline 26 & 2012 & 2 & $\mathrm{M}$ \\
\hline 22 & 2010 & 4 & $\mathrm{~L}$ \\
\hline
\end{tabular}

$\mathrm{L}$ = licenciatura; $\mathrm{M}$ = maestría. Fuente: elaboración propia con base en información recabada durante la investigación. 
con la finalidad de estudiar; el segundo fue enfrentarse a las problemáticas de corte económico para sostenerse fuera de la economía de su núcleo parental.

Hablar o no hablar un idioma indígena en México sigue teniendo repercusiones diferentes. La perspectiva decolonial indica que una de las formas más explícitas de la colonialidad se da a través de la primacía de una o varias lenguas sobre las otras. El no hablar ni entender la lengua se puede explicar, como lo argumenta Yásnaya Aguilar (2015), por la discriminación sistemática que por siglos ha padecido la población indígena. Si bien México es un país plurilingüe, no es posible considerarlo como multilingüe dadas las relaciones asimétricas de poder que están presentes en todos los espacios sociales. Asimismo, es este sector de la población el que enfrenta los mayores índices de exclusión y pobreza. Algunos de los oficios y profesiones que desempeñaron los padres de las académicas fueron comerciantes, albañiles, campesinos y jornaleros, en el país o en Estados Unidos. Sólo dos de los padres contaban con estudios profesionales, uno era maestro de educación primaria y el otro abogado. Por su parte, las madres tuvieron los oficios de comerciantes, campesinas, trabajadoras del hogar y empleadas.

Las historias de vida de las académicas coinciden en algunos aspectos y difieren en otros. Sin embargo, una constante se repite: desde la educación básica sobresalieron como estudiantes de excelencia con los mejores promedios de sus clases. A la academia llegaron las mujeres que lograron sobrevivir al cuello de botella - proceso en el cual la población estudiantil queda excluida del sistema educativo conforme avanzan los grados escolares- que aplica para todas las niñas y jóvenes de este país, y cuyo efecto se acentúa aún más en la población indígena.

\section{Elementos que incidieron en el ingreso como académicas de la UADY y la UVI: capital cultural, expansión y diversificación del SES}

Se toma como punto de partida la función social de la universidad en relación con la colonialidad del saber. Se aborda el ingreso de las académicas a partir de la diferencia según el modelo educativo, dado que algunas instituciones son de corte tradicional y otras de carácter intercultural. Como resultado del discurso indígena que ha tomado fuerza en las últimas décadas la UADY comenzó, desde el año 2010, un proceso de visibilización del alumnado maya. Posteriormente, puso en marcha el Programa Institucional de Estudios del Pueblo y la Cultura Maya (PROIMAYA). La Uvi, por su parte, surge del esfuerzo de la Universidad Veracruzana por revalorar los saberes de los pueblos indígenas y propiciar un proceso de diálogo con los avances del conocimiento de la ciencia occidental.

Para explicar la incidencia que tuvieron los capitales étnicos y lingüísticos de las académicas en su ingreso a las instituciones de educación superior, retomo la idea de Pierre Bourdieu $(2008,2002)$ de mirar el espacio académico como un lugar de lucha de poder. Como se verá más adelante, al ser dos universidades con modelos diferentes, tanto la UADY como la UVI tienen particularidades, pero ambas se guían por el ethos académico que rige a las IEs.

Un campo - podría tratarse del campo científico- se define, entre otras cosas, al precisar aquello que está en juego y los intereses específicos que son irreductibles a lo que se encuentra en juego en otros campos o a sus intereses propios. Para que funcione es necesario que haya algo en juego y gente dispuesta a jugar, que esté dotada de los habitus que implican el conocimiento y reconocimiento de las leyes inmanentes al juego, de lo que está en juego, etcétera (Bourdieu, 2002, p. 119). En esta lógica, el campo universitario reproduce en su estructura el campo de poder cuya organización contribuye a repetir y a consolidar a través de sus propias acciones de selección de actores y de inculcación de valores y de modelos. Si bien estas estructuras rebasan las voluntades individuales, los sujetos o los grupos modifican, en menor o mayor medida, los espacios y las estructuras que conforman los campos o los rehacen cuando impulsan proyectos alternos, como fue el caso de las Universidades Interculturales (UI).

En la UVI, como lo señaló Gunther Dietz (2008), llevar a la práctica un modelo novedoso que incluía otro tipo de saberes fue tarea que generó resistencia por parte de los propios académicos formados en las disciplinas tradicionales. Los conocimientos legítimos están arraigados en los habitus que el personal de la universidad ha ido adquiriendo a través de su formación 
académica. En la UADY, la lucha por el campo se refleja en dos aspectos: primero, en las concesiones que la universidad otorga en cuanto a tener una demanda por personal maya hablante y; segundo, en la contradicción a la que se enfrentan las académicas para combinar las actividades propias del campo académico y las actividades ligadas a espacios comunales.

Sabemos que los sistemas de ciencia y tecnología no son sistemas puramente meritocráticos: rasgos como la condición étnica y de género - pero no sólo estos- influyen en los juegos de poder del campo académico. Los estudios de género acerca del campo científico han llamado la atención sobre cómo estas posiciones desconocen los modos en que la meritocracia ratifica o construye el lugar de poder de algunos sujetos, usualmente como en nuestro caso, de los hombres blanco-mestizos (Díaz y Pérez, 2012). Generalmente

Uno de los supuestos de partida es que, generalmente, en el transcurso de la carrera universitaria o el ingreso a la academia, las y los profesionistas e intelectuales indigenas hacen uso del doble capital cultural que han adquirido: por un lado, la lengua materna o la condición étnica-capital cultural incorporado$y$, por el otro, la formación universitaria - capital cultural institucionalizado- para

ingresar a nichos de empleo en donde desarrollar estas capacidades.

las investigaciones sobre académicas son proclives a observarlas como un grupo uniforme en el que todas se enfrentan al poder masculino. Como nos dice Chandra Mohanty (2008), la diversidad de las mujeres es minimizada por la experiencia compartida de opresión. De modo que las discrepancias materiales, ideológicas, de poder, de clase o de edad se difuminan. La mujer académica es presentada como una categoría unitaria; como una representante universal de todas las académicas, sin matices, contrastes o diferencias. No obstante, el hecho de trabajar para un mismo sector laboral no hace de ellas una categoría homogénea (García, 2000).
Para conocer los elementos que incidieron en el ingreso de las entrevistadas a la academia fue necesario tomar en consideración varias características que propiciaron diferentes trayectorias. Un elemento a resaltar es el hecho de que pertenecen a dos universidades con distintos proyectos educativos respecto a la oferta universitaria y la demanda social a la que pretenden responder.

La expansión y la diversificación del SEs, en el que se contextualizan la UADY y la UVI, enmarcan el ingreso de las académicas a dichas universidades. Además, hay que agregar el análisis de cómo influyeron sus diferentes capitales en su entrada laboral. Tres son los capitales que se consideraron para estudiar su incidencia en el ingreso de las académicas a dichas instituciones: el capital institucionalizado, el lingüístico y el étnico. A sabiendas que la profesión académica exige como mínimo ciertas credenciales para ingresar a su campo, se pretende situar el momento y los elementos que favorecieron o no, el reclutamiento de las entrevistadas.

Seguiré a Pierre Bourdieu (1987) cuando afirma que el capital cultural existe bajo tres formas: en el estado incorporado, es decir, bajo la forma de disposiciones duraderas del organismo; en el estado objetivado, bajo la forma de bienes culturales, y, finalmente, en el estado institucionalizado como forma de objetivación muy particular. Así, el título escolar confiere al capital cultural -que supuestamente debe de garantizarpropiedades totalmente originales.

Si se aborda el capital incorporado desde la colonialidad del saber, se deduce que son justamente estas disposiciones duraderas, como el lenguaje y la cultura de los pueblos indígenas, las que han quedado fuera del currículo escolarizado - en la mayoría de los casos la llamada inclusión queda en la folclorización de la cultura-, con excepción de valiosos proyectos educativos autónomos o interculturales. El capital objetivado, por las condiciones socioeconómicas de las académicas, correspondería a los insumos básicos de familias de clase baja. Por tanto, y ante la carencia de un capital cultural incorporado de los habitus y de los conocimientos considerados legítimos, algunas de las familias de las académicas indígenas vieron en la apuesta educativa un mecanismo que prometía movilidad social a su descendencia, para lo cual invirtieron una cantidad de recursos económicos y sociales que 
aseguraran la obtención de un título en el estado institucionalizado.

Uno de los supuestos de partida es que, generalmente, en el transcurso de la carrera universitaria o el ingreso a la academia, las y los profesionistas e intelectuales indígenas hacen uso del doble capital cultural que han adquirido: por un lado, la lengua materna o la condición étnica - capital cultural incorporado-y, por el otro, la formación universitaria - capital cultural institucionalizado- para ingresar a nichos de empleo en donde desarrollar estas capacidades. Se apunta que el capital cultural incorporado de los intelectuales indígenas no corresponde de manera precisa al considerado legítimo de la cultura y conocimiento dominantes, sino que es un tipo de capital que, paradójicamente, puede ser socialmente desestimado o valorado según el espacio o institución en el cual se manifiestan.

La capitalización de la condición indígena, entendida como el uso estratégico del valor derivado del capital incorporado y simbólicamente activo con el cual las académicas indígenas obtienen beneficios ganados por el dominio de dicho capital, es un elemento que estos sectores de la población han utilizado para estructurar sus trayectorias educativas y profesionales. Tomando en cuenta lo dicho, se ha dividido el ingreso a las IES de las académicas en tres tipologías: a) académicas de la UADY, a partir de considerar su capital institucionalizado y lingüístico, así como la expansión del SEs; b) académicas de la UADY, según su capital institucionalizado y la expansión del SES y; c) académicas de la UVI, al tener presente su capital institucionalizado, étnico y diversificación del sEs.

\section{Capital Institucionalizado de las} académicas indígenas al momento de su inserción profesional a la UADY y a la UVI

La entrada al campo académico requiere, primero, las credenciales que certifiquen al postulante a ocupar un puesto dentro de las instituciones de formación terciaria, es decir, que cuente con los requisitos mínimos solicitados. Jesús Francisco Galaz y Manuel Gil (2009) nos dicen que dos factores influyen en el ingreso a la carrera académica: la dotación social de grados y que al mercado académico lo acompañen otras experien-

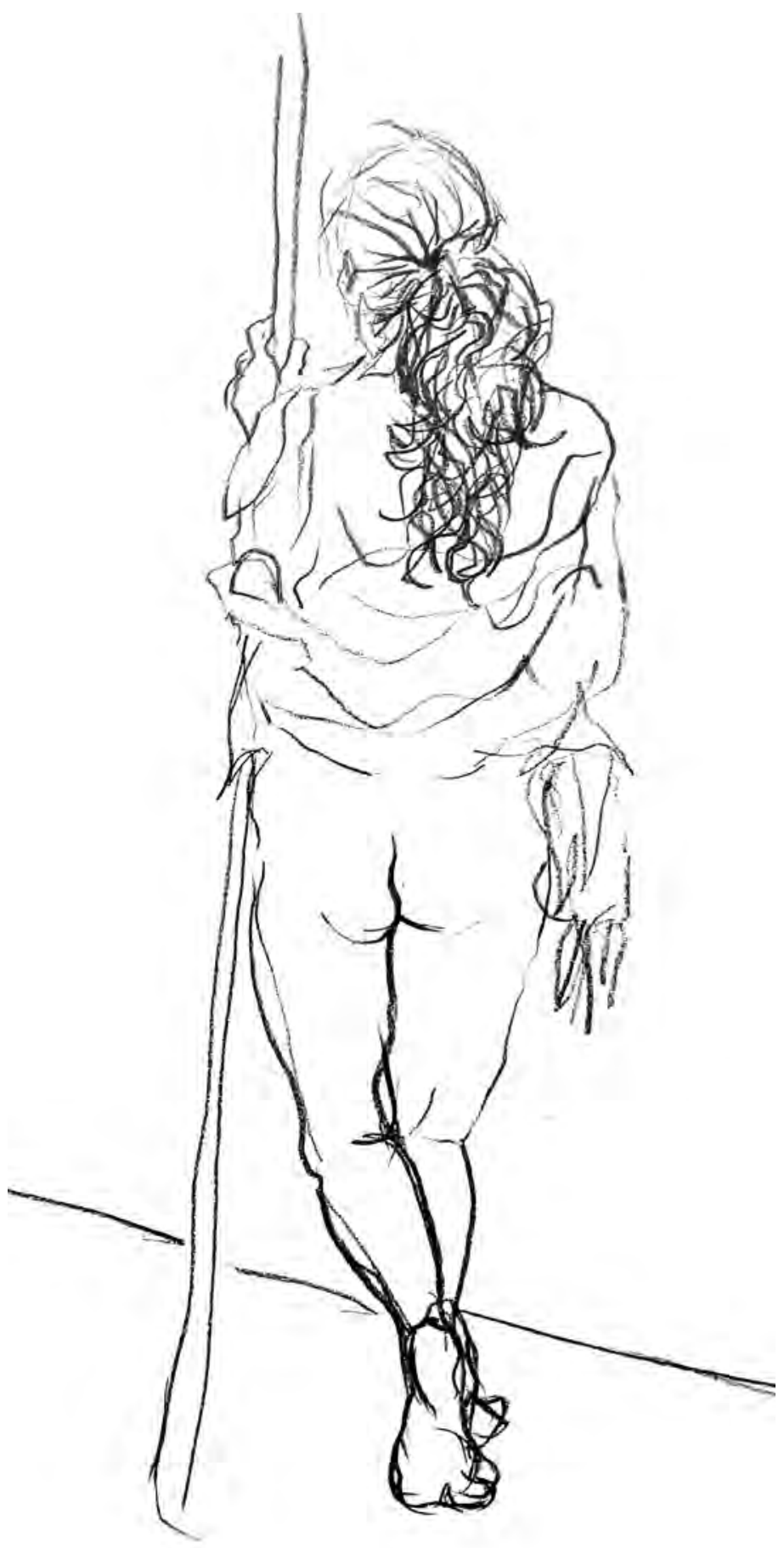


cias laborales apreciadas y reconocidas en términos económicos y de prestigio social.

Un dato relevante es que las tres académicas con mayor antigüedad laboral se integraron a la universidad sin haber obtenido aún el título de licenciatura, como lo muestra el cuadro 2. Este hecho era común en el periodo de expansión del SES, cuando, según Manuel Gil (1994), el 34.7 por ciento de los y las académicas que se incorporaban en ese periodo no contaban con el título de licenciatura. Este fenómeno hizo que se denominara a dicha etapa como "profesionalización salvaje" de la academia, ante la evidencia de que las incorporaciones en la fase expansiva habían abatido, en gran medida, los criterios formales de reclutamiento.

\section{Bourdieu considera que la lengua estándar tiene su origen en el Estado: es éste el que legitima los usos sociales y crea las condiciones para la constitución de un mercado lingüístico unificado, normalizado $y$ dominado por una lengua oficial.}

Este fenómeno no se repitió para las académicas que se incorporaron después del año 2000.

A diferencia de sus colegas de la UADY que se incorporaron en el periodo de expansión acelerada del SES, a las académicas de la UVI les tocó el periodo de diversificación, cuando el gobierno creó las universidades tecnológicas e interculturales para atender una matrícula específica, tanto geográfica como poblacional (ver Cuadro 3). En las últimas dos décadas hubo, en efecto, un cambio de llave en la entrada al oficio académico: el grado máximo exigido a los postulantes (Galaz y Gil, 2012). Se transitó de la "profesionalización salvaje" a un escalamiento en los criterios de acceso conforme a los cuales el posgrado pasó a ser el requisito indispensable para asegurar la profesionalización rápida de la academia, como lo muestra el cuadro tres para nuestro estudio de caso. 
Capitalización de la condición lingüística de las académicas indígenas al ingresar a laborar a la UADY durante el periodo de expansión del SES

El primer aspecto a considerar es la oportunidad que brindó la UADY a las académicas para capitalizar su condición lingüística, es decir, incorporarse a espacios laborales donde solicitaban personal que fuera hablante de alguna lengua maya. Retomando a Pierre Bourdieu (1987), los capitales lingüísticos tienen un valor distinto según se adecuen a las leyes de un mercado profesional, regulado por un conjunto de normas de interacción que reflejan el poder social de los actores que se encuentran en él.

Bourdieu considera que la lengua estándar tiene su origen en el Estado: es éste el que legitima los usos sociales y crea las condiciones para la constitución de un mercado lingüístico unificado, normalizado y dominado por una lengua oficial. No obstante, Enrique Alonso (2005) advierte que el sociólogo francés deja fuera la referencia de acción como una actividad cotidiana, así como la capacidad de los actores para operar en un contexto "produciendo sentido en sus actos particulares de habla por medio de procesos de construcción, negociación y resistencia simbólica, incrustados en comunidades culturales de prácticas compartidas, significados cotidianos y actividades rutinarias particulares" (Alonso, 2005, p.125).

Así, en momentos específicos, las entrevistadas capitalizaron el idioma maya como un bien lingüístico que era requerido y valorado en la UADY. Alarcón (2005) demuestra que, desde la elección racional, cada individuo es capaz de escoger los medios acordes con sus fines, interactúa con otros individuos y, dentro de los condicionantes de las instituciones y reglas de juego, produce resultados colectivos intencionados o no. Cuatro académicas, las de mayor edad y antigüedad laboral, subrayaron la importancia que tuvo el hecho de hablar el maya al momento de ingresar a laborar a la UADY. Ellas narran cómo en las épocas en que fueron contratadas, el hablar un idioma maya fue de suma importancia para el reclutamiento, ya que en ese momento existía una demanda de personal que lo dominara, por lo que dos de ellas ingresaron como ayudantes durante sus estudios de licenciatura.
No obstante, se denota desde la perspectiva decolonial que se adoptó como clave de lectura, los estudios acerca de la población indígena solían inscribirse en la tradición de los estudios indigenistas, es decir, la investigación acerca de los "otros". En esa época, la capitalización lingüística no era la norma, más bien, se produjo gracias a "concesiones" que abrían ciertos espacios donde se demandaba dicho conocimiento. En palabras de Alarcón (2005), las académicas hicieron un uso estratégico de su idioma, lo cual no era una tendencia extensa. Como las mismas entrevistadas lo manifestaron: la negación de la lengua maya era lo común entre la población maya estudiantil de esa época. Las circunstancias fueron diferentes en el segundo grupo de académicas, las del área de educación. Ellas se incorporaron a un nuevo plantel que se abrió en la ciudad de Tizimín en el año 2000; por tanto, sus procesos de ingreso fueron distintos. El factor étnico o lingüístico no fue de relevancia, dado que no había una demanda dirigida a personal con esas características. La mayoría ingresó a la nueva unidad por contactos con antiguos profesores. Los requisitos se habían modificado, los estudios de maestría - con el grado o en vías de graduarse- se habían vuelto indispensables para ser candidata a un puesto académico.

\section{Diversificación del SES y capital étnico de las académicas indígenas al momento de ingresar a laborar a la UVI}

Para el caso de las académicas que ingresaron a la UVI intervino otro elemento significativo: la adscripción étnica, que no estuvo condicionada a sus capacidades lingüísticas, aunque la mayoría entiende y habla su respectivo idioma originario. Por la naturaleza de la IES tanto la adscripción étnica, como la pertenencia regional a la zona, fueron factores significativos en el ingreso de las académicas a la institución. Una decisión estratégica de la universidad era integrar más personal proveniente de los pueblos indígenas, así como egresados de la misma universidad que tuvieran trabajo previo con las comunidades de la zona. Por ello, más que la capacidad lingüística en sí, lo que influyó en el reclutamiento fue la pertenencia a un grupo étnico y la realización de trabajos de investigación y de organización en la zona. 
La particularidad que caracteriza el ingreso de este grupo de académicas a la UVI es la esencia misma de la universidad: primero, se trataba de una propuesta intercultural y; segundo, era un proyecto nuevo. Estas características incidieron en la forma en cómo se fue conformado y consolidado el nuevo campus académico. Gunther Dietz (2008) subraya que los docentesinvestigadores eran contratados, no por su procedencia étnica, sino en función de sus rasgos profesionales y, sobre todo, de su arraigo y conocimiento de la región. Aun así, señala que la precariedad en la contratación del profesorado generó una cierta fluctuación en las plantillas regionales.

Al ser un campo académico, en términos de Bourdieu, donde los actores se disputan los lugares disponibles, un elemento que las académicas consideraron benéfico para su ingreso, fue el étnico. Si bien Dietz (2008) argumenta que la adscripción étnica no se superpone al capital institucionalizado, las académicas afirman que su ingreso fue justo en el momento en que se produjo un cambio de director general, época en la cual hubo una notable incorporación de personal con adscripción étnica y egresados de las primeras generaciones de la UVI. Laura Mateos y Gunther Dietz (2015) nos dicen que al ser la institución una IEs de corte intercultural, fueron muchos los procesos de renegociación en diferentes aspectos. Ello los obligó a repensar - junto con los propios jóvenes universitarios- las nociones clásicas de lo letrado, lo intelectual y del ethos profesional.

\section{Anotaciones finales}

Al dar continuidad al análisis de las preguntas e hipótesis que se plantearon inicialmente, se concluye que el ingreso de académicas indígenas en la UVI y la UADY estuvo determinado tanto por la expansión y diversificación del SES, como por el uso que ellas hicieron de sus diversos capitales culturales. Se demostró que las historias de éxito no se pueden contar sólo a través de las personas, sino que dependen también de un contexto histórico social.

A lo largo del texto se mostró que el ingreso a la academia y la capitalización de la condición étnicolingüística se han dado de tres formas. La primera, es la de las académicas hablantes un idioma originario a las que se les permitió insertarse en proyectos donde ese conocimiento era requerido. La segunda, es la de las académicas que no son hablantes la lengua, pero se reconocen como parte del pueblo maya y para quienes la condición étnico-lingüística no estuvo relacionada con su ingreso a los espacios académicos. La tercera, las académicas indígenas que ingresaron a una institución intercultural de nueva creación, en donde la condición étnico-lingüística potencializaba su capital institucionalizado.

Plantear la investigación entrevistando a académicas insertas en dos modelos de universidad, permitió analizar el tema étnico más allá de los sujetos. Es decir, sirvió para conocer cómo las IES abordan las temáticas étnicas en su modelo educativo. Al ser una de corte tradicional y la otra intercultural, las diferencias fueron notables y significativas. La universidad es una de las instituciones en las que se plasma claramente la colonialidad del saber dado que fue creada bajo las formas eurocéntricas de conocimiento científico. Es una institución profundamente tradicional en muchos sentidos, la Universidad Autónoma de Yucatán no es la excepción. Como lo indicamos, hasta años muy recientes, la universidad no instrumentaba ningún programa que visibilizara a la población maya o que incluyera o reconociera otros tipos de saberes.

Para algunas de las académicas de la UADY, el uso del capital lingüístico fue factible dado que ingresaron durante la expansión del sES. Si bien no era una IES de corte intercultural, en esos momentos requería intérpretes del maya para las investigaciones que se realizaban en comunidades indígenas. Esto les dio la posibilidad de integrarse, primero, como ayudantes y, posteriormente, como docentes.

La capitalización lingüística de las entrevistadas está situada en lo que se ha denominado en este texto, concesiones dentro del campus académico. No obstante, este fenómeno sólo fue posible si a dicha capitalización se le sumaba el capital institucionalizado requerido, ya que la lógica de los campus y departamentos funcionaba acorde a una universidad de corte tradicional. En el otro grupo, se encuentran las académicas que ingresaron al campus nuevo en la ciudad de Tizimín. Lo que pudimos observar ahí fue que las condiciones de ingreso para ellas, más allá de las concesiones lingüísticas, siguieron las tenden- 
cias nacionales de endogamia y profesionalización académica.

Para el caso de la UVI, el oficio académico de las entrevistadas está en estrecha relación con el modelo intercultural. Es decir, el ethos académico se ponía en cuestión y se reformaba en los momentos de ingreso. Ellas fueron las profesionistas a quienes les tocó poner en marcha un nuevo modelo de educación universitaria. Para este grupo de académicas, la capitalización étnica está vinculada a un proyecto gestante que pretendía incluir en sus planes de estudios nuevos saberes y conocimientos.

Sin embargo, como proyecto nuevo y como sucedió en muchas de las UI, las condiciones laborales que enfrenta el personal son precarias. Todas ellas manifestaron tener contratos eventuales, aunque cuatro sean de tiempo completo y dos trabajen por asignatura, la inestabilidad laboral es una preocupación que afloró en las entrevistas. Asimismo, un proyecto de esta naturaleza significó que diferentes voces - de intelectuates de políticos y líderes indígenas- se pronunciaran a favor o en contra de las UI creadas bajo un contexto político conflictivo y con poca legitimación sociah

Finalmente, observamos que la capitálización étnico-lingüística tuvo incidencia en el ingréso a la UVI y a la UADY para algunas de las académicas, pero no así en su permanencia. Una vez dentro, la subsecuente adquisición de grados, así como la producción académica, fueron loselementos que determinaron su ascenso a categorías más altas o a puestos de coprdinación en ambas universidades. Para aquellas en que la condición étnico-lingüística tuvo incidencia en su ingreso, se observa que hubo una continuidad en su quehacer académico, ya que las temáticas acerca de los pueblos indígenas sustentaron sus principales líneas de investigación.

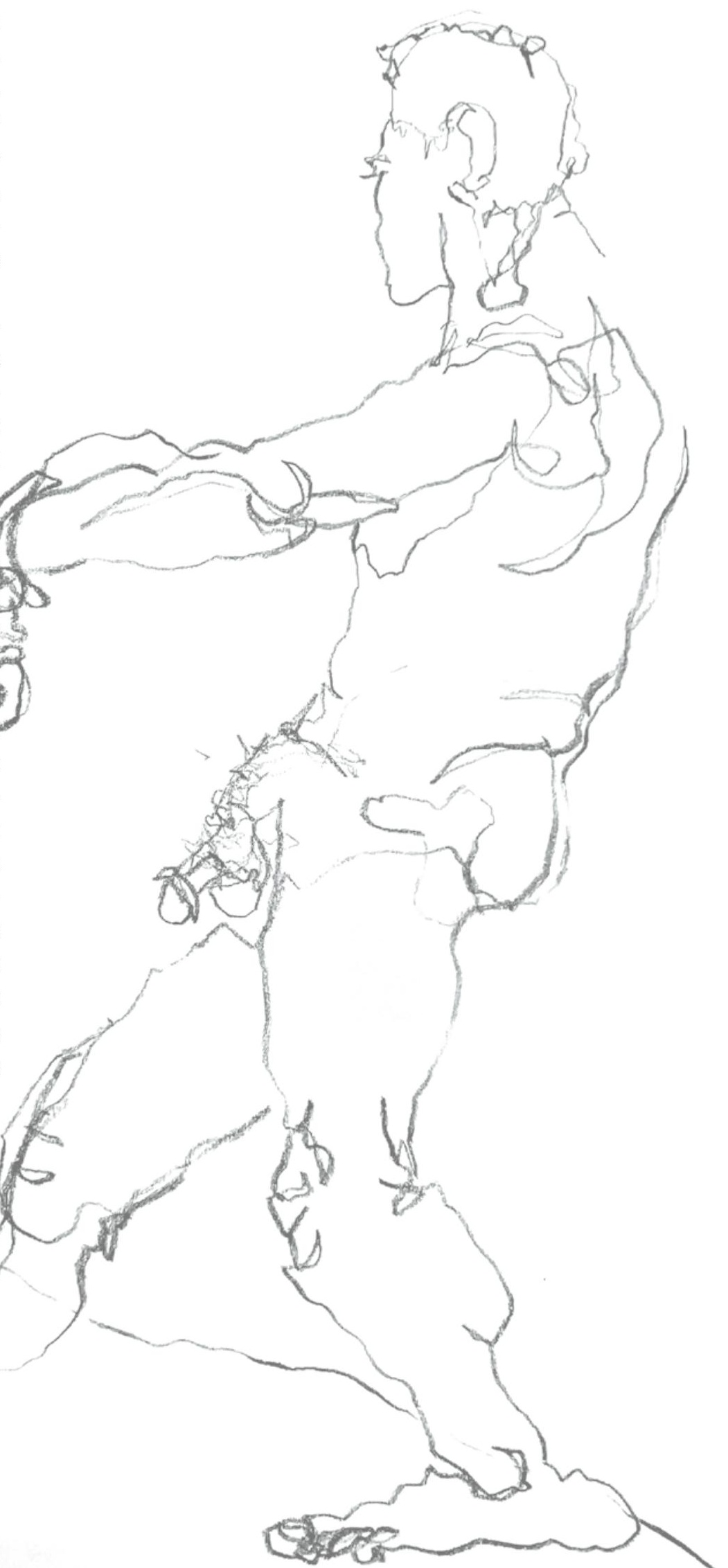




\section{Bibliografía}

Aguilar, Y. (1 de agosto de 2015). ¿Es México un país multilingüe?. El país, disponible en https://archivo.estepais.com/site/2015/esmexico-un-pais-multilingue/.

Alonso, E. (2005). Los mercados lingüísticos o el muy particular análisis sociológico de los discursos de Pierre Bourdieu. Estudios de Sociolingüística, 3(1),111-131.

Alarcón, A. (2005). Los mercados lingüísticos. Aportaciones desde la perspectiva de la elección racional. Papers: revista de sociología, 89-109.

Bourdieu, P. (1987). Los tres estados del capital cultural. Sociológica, Universidad Autónoma Metropolitana, (5), 11-17.

Bourdieu, P. (2000). La dominación masculina. Barcelona: Madrid, Editorial.

Bourdieu, P. (2002). Campo de poder, campo intelectual. Argentina: Montressor.

Bourdieu, P. (2008). Homo academicus. Argentina: Siglo XXI editores.

Díaz, A., y Pérez, P. (2012). Testigos modestos y poblaciones invisibles en la cobertura de la genética humana en los medios de comunicación colombianos, Interface - Comunicação, Saúde, Educação., 16(41), 451-67.

Dietz, G. (2008). La experiencia de la Universidad Veracruzana Intercultural. En Daniel, M. (Coord.), Diversidad Cultural e Interculturalidad en Educación Superior. Experiencias en América Latina. Venezuela: UNESCO-IELSAC.

Dussel, E. (1992). 1492: el encubrimiento del otro: hacia el origen del mito de la modernidad. La Paz: Plural Editores, UMSA.
Galaz, J. y Gil, M. (2012). La profesión académica en México: un oficio en proceso de reconfiguración. En Galaz, J. y Gil, M., Padilla, L., Sevilla, J., Arcos, J., y Martínez, J., (Coords.), La reconfiguración de la profesión académica en México. México: Universidad Autónoma de Sinaloa, Universidad Autónoma de Baja California.

García, P. (2000). Agenda teórica para el estudio de las mujeres académicas. Sociológica, 15(44),163-179.

Gil, A. et al. (1994). Los rasgos de la diversidad. Un estudio sobre los académicos mexicanos. México: Universidad Autónoma MetropolitanaAzcapotzalco.

Mateos, L. y Dietz, G. (2011). Universidades Interculturales en México. Balance crítico de la primera Década. Revista Mexicana de Investigación Educativa, 21(70), 683-690.

Mateos, L. y Dietz, G. (2015). ¿Qué de intercultural tiene la "universidad intercultural"? Del debate político-pedagógico a un estudio de caso veracruzano. Relaciones, 141, 13-45.

Mohanty, C. (2008). Bajo los Ojos de Occidente: Feminismo Académico y Discursos Coloniales. En Suárez, T. y Hernández A. (Eds.), Descolonizando el Feminismo: Teorías y Prácticas desde los Márgenes. Madrid: Cátedra.

Oehmichen, C. (1999). La relación etnia-género en la migración femenina rural-urbana: mazahuas en la Ciudad de México. Iztapalapa. Revista de Ciencias Sociales y Humanidades, 45, 7-132.

Quijano, A. (2007). Colonialidad del poder y clasificación social. En C. Santiago y R. Grosfoguel (Comps.), El giro decolonial: reflexiones para una diversidad epistémica más allá del capitalismo global. Bogotá: Siglo del Hombre Editores.
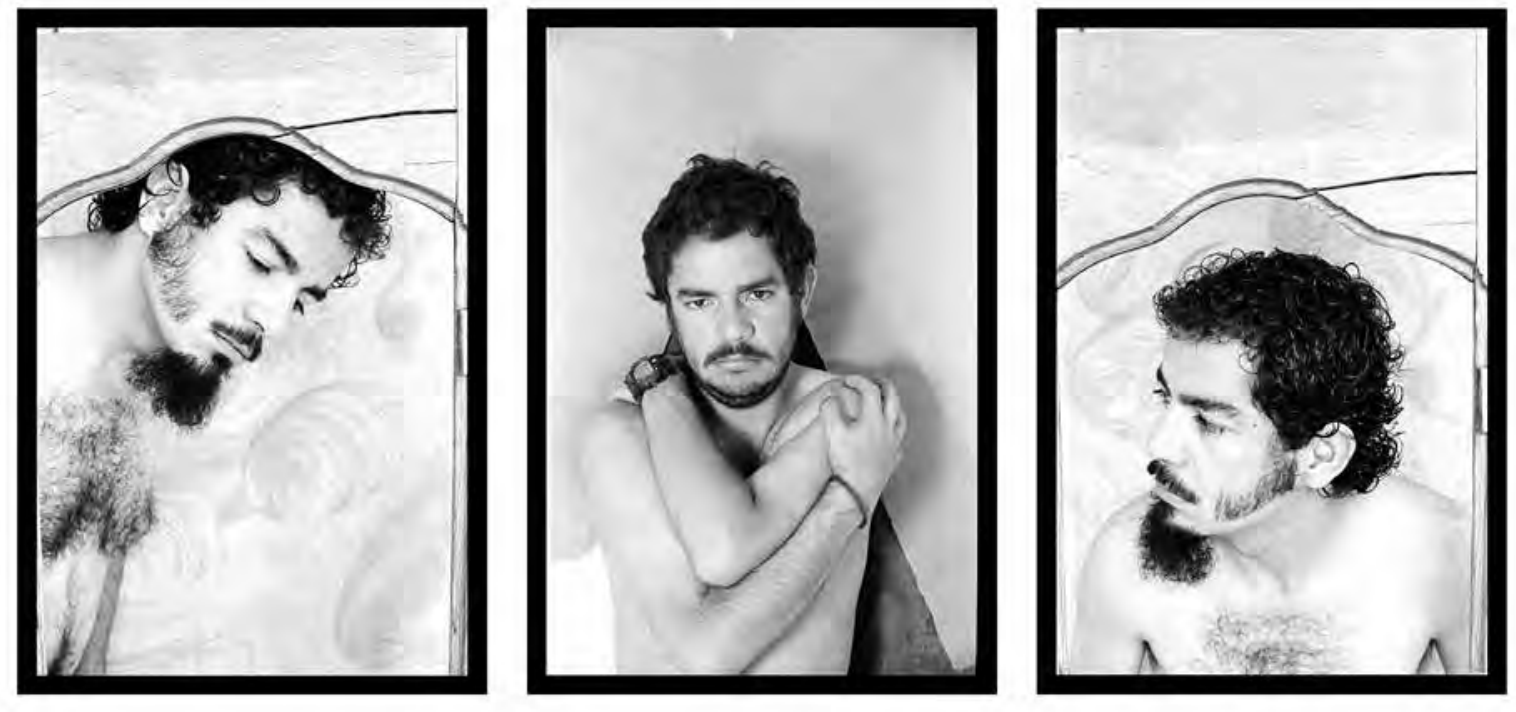

El uso de fármacos da la posibilidad a las personas de llegar a viejas. 